\title{
Correspondence between try-in pastes and resin cements, and color stability of bonded lithium disilicate disks
}

\section{Rafael Soares DINIZ(a) Letícia Fecury Bogéa de ALBUQUERQUE(a) \\ Rudys de Jesus Rodolfo TAVAREZ ${ }^{(a)}$}

Eduardo Buozzi MOFFA(a) Andréa Dias Neves LAGO(b) (iD Letícia Machado GONÇALVES(a)

(a) Universidade CEUMA, Postgraduate program in Dentistry, São Luís, MA, Brazil.

(b) Universidade Federal do Maração - UFMA, Graduate program in Dentistry, São Luís, MA, Brazil.

Declaration of Interests: The authors certify that they have no commercial or associative interest that represents a conflict of interest in connection with the manuscript.

Corresponding Author:

Letícia Machado Gonçalves

E-mail: lets.mg@gmail.com

htrps://doi.org/10.1590/1807-3107bor-2019.vol33.0009

Submitted: April 23, 2018

Accepted for publication: December 12, 2018

Last revision: January 09, 2019
Abstract: This study investigates the color correspondence of resin cements and try-in pastes, and the color stability of bonded lithium disilicate ceramic disks. Resin composite disks were fabricated $(\mathrm{n}=$ 36) to serve as the background for lithium disilicate disks prepared in two thicknesses ( 0.5 and $1.0 \mathrm{~mm}, \mathrm{n}=18$ each). Two brands were used for try-in and cement procedures: Variolink Veneer and AllCem Veneer. For baseline, water was applied between the ceramic disks and their respective backgrounds to achieve the control group. This set was subjected to color measurement using an intraoral measurement device (T0). The try-in was inserted between background and ceramic, and this set was subjected to color measurement (T1). After adhesive procedures, the ceramic disk was placed under cement, and color measurement was performed with uncured cement (T2) and $24 \mathrm{~h}$ after light-curing (T3). Each set was immersed in distilled water and thermal-cycled, with color measurement being performed after 10,000 (T4) and 20,000 (T5) cycles. Color differences were calculated by CIELab $\left(\mathrm{rE}_{\mathrm{ab}}\right)$ and CIEDE2000 $\left(\mathrm{rE}_{00}\right)$. Data were analyzed by two-way ANOVA for repeated measurements and Tukey's test $(\alpha=5 \%)$. There was color correspondence of try-in and resin cement for the Variolink system, regardless of the ceramic thickness ( $p>0.05)$. For the AllCem system, the thickness significantly influenced the color measurement $(\mathrm{p}<0.001)$. The Variolink system also demonstrated color stability after 20,000 thermal cycles with $\mathrm{rE}_{\mathrm{ab}}<3.46$ and $\mathrm{rE}_{00}<2.25$. It was concluded that the color correspondence between a try-in and its respective cement may vary according to resin cement composition.

Keywords: Resin Cements; Color; Ceramics.

\section{Introduction}

A primary goal of current aesthetic dentistry is obtaining healthy tooth structures integrated with biologic and long-term functional requirements. ${ }^{1}$ Accordingly, ceramic veneers have characteristics capable of mimicking the natural structures and have become popular for improving the appearance of anterior teeth. ${ }^{2}$ This technique allows for less-aggressive tooth removal than full coverage restorations, and demonstrates excellent clinical performance in terms of periodontal reaction and biocompatibility, which favor a healthy gingival response. ${ }^{1,3,4,5,6}$ 
It is known that the low strength and high brittleness of ceramics made them dependent on metal reinforcement. Over the years, these metal copings have been replaced by metal-free reinforced ceramics. Therefore, the use of ceramics veneers reinforced with lithium disilicate may be indicated for cosmetic restorative procedures. ${ }^{3,4,5}$ In order to obtain a durable bonding strength for lithium disilicate ceramic veneers, tooth reduction should remain within the enamel layer, which is $0.5-1.0$ $\mathrm{mm}$ thick. As a result, veneers are ideally thin and relatively translucent. ${ }^{7,9,9}$

The translucency of veneers adds another level of complexity to the shade-matching process because ceramics allow more light to enter and scatter within the material, giving the underlying dental structure a significant influence on the final color. ${ }^{6,8}$ Several factors may also affect the final reproduction, including the combination of ceramic shade, thickness and degree of translucency, ${ }^{10,11,12}$ the color of the underlying and surrounding hard tissues, the color and thickness of the luting agent, ${ }^{12,13,14}$ and the aging process of adhesive systems. ${ }^{15,16}$

From an aesthetic point of view, it is essential to gain the approval of the patient before final cementation takes place. ${ }^{17}$ However, it is especially challenging for dentists to match the optical properties of natural teeth and to predict the resultant color of ceramic veneers in composing a harmonious appearance. ${ }^{6,16,18}$ Several approaches have been described for previewing and/ or adjusting the final appearance of restorations.,19 Manufacturers have introduced adhesive systems for ceramic veneers that include various colors of resin cements and their corresponding water-soluble try-in pastes. ${ }^{19,20}$ They have claimed that resin cements of various shades can be used to modify the final color of the veneers to attain color matching. ${ }^{20,21}$ In addition, try-in pastes could be used as indicators of the final color and as a guide to choosing an appropriate color of cement agents. ${ }^{22,23,24,25,26}$

Several studies have reported that, in general, no difference was observed between the color perception of the try-in pastes and their respective cements. ${ }^{10,16,27}$ However, most were conducted directly in the cement layer, with no simulation of a ceramic restoration or standardization of cement thickness. ${ }^{27}$ Also, other studies used indirect resin composites rather than ceramic ceramics, ${ }^{10}$ or did not obeyed all adhesive steps recommended by manufacturers ${ }^{16}$ which compromises the clinical relevance of the results.

Therefore, there is a lack of adequate information on whether or not try-in pastes can reproduce the final shade of their corresponding cements, ${ }^{16,24}$ especially when factors such as commercial brand, ceramic thickness and aging process are considered. Taking this into account, a comprehensive determination of whether such factors affect the correspondence of try-in pastes and resin cements could optimize color selection..$^{25}$ Thus, this study investigates the color correspondence of resin cements with their corresponding try-in pastes, and the color stability of bonded lithium disilicate disks prepared in two different thicknesses (0.5 and $1.0 \mathrm{~mm}$ ).

\section{Methodology}

\section{Resin background disk fabrication}

Disk-shaped resin composites (Llis; FGM, Joinville, Brazil) in shade A2 served as the background colors to mimic the prepared enamel substrates $(n=36)$. The disks were fabricated using a stainless steel matrix (10 mm diameter $\times 2.0 \mathrm{~mm}$ thickness) to obtain a uniform background. The resin was inserted in a $2.0 \mathrm{~mm}$ single layer, having been lightly pressed with a matrix polyester strip and a glass slide. The resin composite was light-cured for $40 \mathrm{~s}$ with an LED light-curing unit (LED 3MESPE, St Paul, MN), with a mean light intensity of $1400 \mathrm{~mW} / \mathrm{cm}^{2}$. Each disk was then ground in a horizontal polisher (model APL-4; Arotec, São Paulo, Brazil) using progressively smoother aluminum oxide papers $(320,400$, and 600 grit) for $1 \mathrm{~min}$ each. For standard purposes, the surface roughness of all disks was analyzed by a rugosimeter (Surfcoder SE1200®; Mitutoyo Corp., Tokyo, Japan) with accuracy close to the nearest 0.01 $\mu \mathrm{m}$ and calibrated at a cutoff value of $0.8 \mathrm{~mm}$ and 2.4 $\mathrm{mm}$ percussion of measure at $0.5 \mathrm{~mm} / \mathrm{s}$. The mean of three measurements for each disk was calculated, and the surface roughness was standardized at 0.88 $\pm 0.07 \mu \mathrm{m}$. After these measurements, the disks were ultrasonically cleaned in purified water for $20 \mathrm{~min}$, and stored in distilled water at $37^{\circ} \mathrm{C}$ for $24 \mathrm{~h}$. 


\section{Ceramic disks fabrication}

Disk-shaped lithium disilicate (IPS E.Max Press; Ivoclar, Schaan, Liechtenstein) in shade A2 and 10 in diameter were fabricated by the lost-wax technique in accordance with the manufacturer's instructions. Wet silicone carbide papers $(600-, 800-, 1000-, 1500-$ grit) were used to polish and achieve a thickness of $0.5 \mathrm{~mm}(\mathrm{n}=18)$ or $1.00 \mathrm{~mm}(\mathrm{n}=18)$. The disk thickness was confirmed with a digital micrometer (Mitutoyo Corp., Tokyo, Japan) and the disks were polished with standardized rubber disks (Exacerapol; Edenta, $\mathrm{Au}$, Switzerland) numbers 301, 306, and 322, for 30 $\mathrm{s}$ each. The polishing was performed in circular motions from the center to the periphery of the disk. Finally, a self-glazing process was performed at the manufacturer's recommended temperature. No staining was used in the fabrication procedure. The disks were ultrasonically cleansed in purified water for $20 \mathrm{~min}$, and stored in distilled water at $37^{\circ} \mathrm{C}$ for $24 \mathrm{~h}$.

\section{Application of try-in pastes and resin cements}

Two commercial brands were used for try-in and cement procedures, those being Variolink Veneer (Ivoclar, Schaan, Liechtenstein) in shade +1 and AllCem Veneer (FGM, Joinvile, Brazil) in shade A2. For baseline purposes, a refractive liquid (refractive index $\sim 1.50$, such as water) was applied between the ceramic disks and their respective resin backgrounds to act as the control group. This set background/ liquid/ceramic was submitted for color measurement using a calibrated intraoral measurement device (Easyshade Advance 4.0; Vita Zahnfabrik, Germany), (Baseline, T0).

The try-in paste was then inserted under the resin background and the ceramic disks ( 0.5 or 1.0 $\mathrm{mm}$ thickness) and was pressed lightly for $5 \mathrm{~s}$ with a $25 \mathrm{~g}$ block in the center of the disk until a digital micrometer measured a $100 \pm 1 \mu \mathrm{m}$ thick layer. The excess was removed with a spatula and the set background/try-in/ceramic was subjected to color measurement (T1). After this procedure, the ceramic disk was removed and both ceramic and background surfaces were washed with an air/water spray for 30 $\mathrm{s}$ and dried with absorbent paper.
Following adhesive protocols, the resin disk was etched with 37\% phosphoric acid (Condac 37; FGM, Joinvile, Brazil) for $30 \mathrm{~s}$, washed with an air/water spray for $30 \mathrm{~s}$, and coated with the adhesive system recommended by the resin cement manufacturer; Excite (Ivoclar, Schaan, Liechtenstein) was used for Variolink Veneer and Ambar (FGM, Joinvile, Brazil) was used for AllCem Veneer. Both adhesives were applied for $20 \mathrm{~s}$ and light-cured for $10 \mathrm{~s}$ (LED 3MESPE, St Paul, MN). In addition, the ceramic disks were etched with $10 \%$ hydrofluoric acid (Condac 10; FGM, Joinvile, Brazil) for $20 \mathrm{~s}$, washed with an air/water spray for $30 \mathrm{~s}$, and coated with the silane recommended by the resin cement manufacturer; Monobond (Ivoclar, Schaan, Liechtenstein) was used for Variolink Veneer while Prosil (FGM, Joinvile, Brazil) was used for AllCem Veneer, both with an application time of $60 \mathrm{~s}$. A thin coat of cement from the respective brand was applied to the resin disk. The ceramic disk was pressed lightly for $5 \mathrm{~s}$ with a $25 \mathrm{~g}$ block in the center of the disk until a digital micrometer measured a $100 \pm 1 \mu \mathrm{m}$ thick layer. The excess was removed with a spatula and light-curing (LED 3MESPE, St Paul, USA) was performed for 40 $\mathrm{s}$ with the tip of the light-curing unit positioned perpendicular to the ceramic disk surface. Color measurement of background/cement/ceramic set was performed with the uncured cement (T2) and $24 \mathrm{~h}$ after cementation (T3).

\section{Thermal cycling process}

In order to investigate the color stability of the different resin cements, each set background/cement/ ceramic disk was immersed in distilled water and subjected to thermal cycling for 20,000 cycles (Biopdi, São Carlos, Brazil). Each thermal cycle consisted of alternating immersions in distilled water at $5 \pm$ $5^{\circ} \mathrm{C}$ and $55 \pm 5^{\circ} \mathrm{C}$ for $30 \mathrm{~s}$ at each dwell time. Color measurement was performed after 10,000 (T4) and 20,000 (T5) thermal cycles.

\section{Color measurement and analyses}

The color measurement was evaluated using the color coordinates $L^{*}, a^{*}$ and $b^{*}$ based on the Commission Internationale de l'Éclairage (CIE) system, as measured with a portable intraoral measurement 
device (Easyshade Advance 4.0; Vita Zahnfabrik). The CIELab system is based on three parameters for defining color: $\mathrm{L}^{*}, \mathrm{a}^{*}$ and $\mathrm{b}^{*}$, where $\mathrm{L}^{*}$ represents lightness from 0 (black) to 100 (perfect white), a* represents red (positive value) or green chroma (negative value), and $b^{*}$ represents yellow (positive value) and blue chroma (negative value). The color difference between two color readings (i.e. $\mathrm{rE}_{\mathrm{ab}}$ ) was calculated using the formula: $\mathrm{rE}_{\mathrm{ab}}=\left[\left(\mathrm{rL}^{*}\right)^{2}+\left(\mathrm{ra}^{*}\right)^{2}+\right.$ $\left.\left(\mathrm{rb}^{*}\right)^{2}\right]^{1 / 2}$, where the $\mathrm{r}$ values represent the differences measured in $L^{*}$, $a^{*}$ and $b^{*}$ values between two color readings at the different time-points. ${ }^{26}$

The CIELab values were converted into CIEDE2000 notation formula, ${ }^{27}$ which was additionally used to calculate color difference by using the equation: $\mathrm{rE}_{00}$ $=\left[\left(\mathrm{rL}^{\prime} / \mathrm{K}_{\mathrm{L}} \mathrm{S}_{\mathrm{L}}\right)^{2}+\left(\mathrm{rC}^{\prime} / \mathrm{K}_{\mathrm{C}} \mathrm{S}_{\mathrm{C}}\right)^{2}+\left(\mathrm{rH}^{\prime} / \mathrm{K}_{\mathrm{H}} \mathrm{S}_{\mathrm{H}}\right)^{2}+\mathrm{R}_{\mathrm{T}}\left(\mathrm{rC}^{\prime} / \mathrm{K}_{\mathrm{C}} \mathrm{S}_{\mathrm{C}}\right)\right.$ $\left.\left(\mathrm{rH}^{\prime} / \mathrm{K}_{\mathrm{H}} \mathrm{S}_{\mathrm{H}}\right)\right]^{1 / 2}$, where $\mathrm{rL}^{\prime}, \mathrm{rC}^{\prime}$ and $\mathrm{rH}^{\prime}$ are differences in lightness, chroma, and hue two color readings at the different time-points. $\mathrm{R}_{\mathrm{T}}$ represents the rotation function that accounts for the interaction between chroma and hue differences in the blue region. $S_{L}, S_{C}$ and $S_{H}$ represents weighting functions used to adjust the total color difference for variation in perceived magnitude with variation in the location of the color coordinate difference between two color readings at the different time-points. $\mathrm{K}_{\mathrm{L}}, \mathrm{K}_{\mathrm{C}}$, and $\mathrm{K}_{\mathrm{H}}$ are correction terms for the experimental conditions. $\mathrm{rE}_{\mathrm{ab}}$ and $\mathrm{rE}_{00}$ values lower than 3.46 and 2.25, respectively, represented clinically imperceptible color changes. ${ }^{28}$

Before each measurement session, the intraoral measurement device was calibrated with a white reflectance standard supplied by the manufacturer. To avoid color measurement errors caused by changes in position, a customized silicone mold was used to standardize the position in the disks. The silicon mold was fitted repeatedly at the same position on the sensor of the intraoral measurement device. All shade analyses were conducted by placing the sets on a gray-colored rubber surface, and the values of each measurement were based on an average of five readings of the same set.

The color analyses for each measurement set was calculated as follows for $\mathrm{rE}_{\mathrm{ab}}$ and $\mathrm{rE}_{00}: \mathrm{rE}_{\mathrm{T} 1 \mathrm{~T} 0}$ (difference between try-in paste and baseline); $\mathrm{rE}_{\mathrm{T} 2-\mathrm{T} 1}$ (difference between cement before light-curing and try-in paste); $\mathrm{rE}_{\text {T3-T1 }}$ (difference between cement $24 \mathrm{~h}$ after light- curing and try-in paste); $\mathrm{rE}_{\mathrm{T4}-\mathrm{T} 3}$ (difference between cement $24 \mathrm{~h}$ after light-curing and 10,000 thermal cycles); and $\mathrm{rE}_{\mathrm{T5-тз}}$ (difference between cement $24 \mathrm{~h}$ after light-curing and 20,000 thermal cycles).

\section{Statistical analysis}

All tests were performed in triplicate on three different days. Data were analyzed by two-way analysis of variance (ANOVA) for repeated measurements followed by Tukey's test at a 5\% significance level. The results were statistically analyzed by the SAS/ LAB software package (SAS Software, version 9.0; SAS Institute Inc., Cary, NC, USA). Assumptions of the equality of variances and the normal distribution of errors were checked using the Kolmogorov-Smirnov test. Data were analyzed by one-way ANOVA for repeated measurements followed by Tukey's HSD test, considering the commercial brand and thickness as study factors. The significance level was set at 5\% for all tests.

\section{Results}

The results of $\mathrm{rE}_{\mathrm{ab}}$ and $\mathrm{rE}_{00}$ measurements on ceramic disks with thicknesses of $0.5 \mathrm{~mm}$ or 1.0 $\mathrm{mm}$ are presented in Tables 1 and 2, respectively. Considering that there is color correspondence in values of $\mathrm{rE}_{\mathrm{ab}}$ lower than 3.46 and $\mathrm{rE}_{00}$ lower than $2.25^{28}$, it was verified color correspondence between the try-in paste and the resin cement of the Variolink Veneer system for the ceramics of both $0.5 \mathrm{~mm}$ and 1.0 $\mathrm{mm}$ thickness. Statistical differences were observed in $\mathrm{rE}$ values before and after light-curing for this system $(p<0.05)$, but the data were not sufficient to define clinical perceptible changes. For this cement, the thickness of the ceramic disk did not significantly influence the color measurement process at all analysis times $(\mathrm{p}>0.05)$.

For the AllCem Veneer system, there was color correspondence only in the $1.0 \mathrm{~mm}$ ceramic disk (p $>0.05$ ). For this system, the thickness significantly influenced the color measurement process, with statistically significant differences for ceramics of $0.5 \mathrm{~mm}$ and $1.0 \mathrm{~mm}$ thickness ( $\mathrm{p}<0.001)$.

With regard to the color stability of the resin cement after thermal cycling, there was no statistical 
difference for the Variolink Veneer system ( $p>0.05)$ for both ceramics of $0.5 \mathrm{~mm}$ (Figure 1 ) and $1.0 \mathrm{~mm}$ (Figure 2), and all $\mathrm{rE}_{00}$ values were clinically imperceptible $(<2.25)$. For the AllCem Veneer system, values $>2.25$ were observed in all values of $\mathrm{rE}_{00}$, with a statistically significant difference for $0.5 \mathrm{~mm}$ thick ceramics ( $\mathrm{p}$ $<0.05)$.

\section{Discussion}

The present experiment was an in vitro study that evaluated the color correspondence of the resin cements with their corresponding try-in pastes before and after $24 \mathrm{~h}$ light-curing. It is important to mention that the color measurements were performed through a ceramic disk obeying all adhesive steps in order to simulate clinical procedures as closely as possible.

Most previous studies evaluating the color of resin cements were conducted directly in the cement layer, with no simulation of a ceramic restoration or standardization of cement thickness. ${ }^{27}$ Thickness of the cement layer is a sensitive parameter for color measurement, and different resin cement thicknesses can alter translucency values, and consequently the final color of the restoration. ${ }^{29,30,31,32}$ A moderate pressure was loaded on the complexes to prevent the formation of air bubbles within the inner layers, and to create a uniform thickness. Considering the possibility of a thin air layer occupying the interspace of ceramic and resin disks, which would dramatically increase the difference of the color measurements, a refractive liquid was applied into the interspace to maintain an optical connection, ${ }^{6,10}$ and the color coordinates of the refractive liquid applied complexes were set as a baseline.

Colorimeters such as the one used to conduct the color measurements in the present study are capable of spotting color differences that are not always detectable to the human eye. Visual evaluation of the color is not sufficient, since it depends on the

Table 1. CIELab $\left(\mathrm{rE}_{\mathrm{ab}}\right)$ color measurement observed in each experimental set (mean \pm STD).

\begin{tabular}{|c|c|c|c|c|}
\hline \multirow{2}{*}{ Groups } & \multirow{2}{*}{ Thickness } & \multicolumn{3}{|c|}{ Time-points } \\
\hline & & $\mathrm{rE}_{\mathrm{T} 1-\mathrm{TO}}$ & $r E_{T 2-T 1}$ & $r E_{T 3-T 1}$ \\
\hline \multirow{2}{*}{ AllCem veneer } & $0.5 \mathrm{~mm}$ & $4.40 \pm 0.65(\mathrm{~A}, \mathrm{a})$ & $14.82 \pm 2.16(\mathrm{~A}, \mathrm{~b})$ & $12.63 \pm 3.48(\mathrm{~A}, \mathrm{~b})$ \\
\hline & $1.0 \mathrm{~mm}$ & $2.70 \pm 1.55(B, a)$ & $3.22 \pm 1.42(B, a)$ & $3.49 \pm 1.65(B, a)$ \\
\hline \multirow{3}{*}{ Variolink veneer } & $0.5 \mathrm{~mm}$ & $1.12 \pm 0.87(\mathrm{~A}, \mathrm{ab})$ & $2.50 \pm 1.16(A, b)$ & $1.63 \pm 1.16(\mathrm{~A}, \mathrm{a})$ \\
\hline & & & & \\
\hline & $1.0 \mathrm{~mm}$ & $1.87 \pm 1.07(\mathrm{~A}, \mathrm{ab})$ & $2.93 \pm 1.53(\mathrm{~A}, \mathrm{~b})$ & $1.14 \pm 0.43(\mathrm{~A}, \mathrm{a})$ \\
\hline
\end{tabular}

Different uppercase letters indicate statistically significant differences regarding $\Delta \mathrm{E}_{\mathrm{ab}}$ values in terms of thickness $(0.5 \mathrm{and} 1.0 \mathrm{~mm}$ thick) within a given commercial brand (Student T-test, $p<0.05$ ). Different lowercase letters indicate statistically significant differences regarding $\Delta \mathrm{E}_{\mathrm{ab}}$ value in terms of time-points (one-way ANOVA for repeated measurements, $p<0.05$ ). $r \mathrm{E}_{T 1-T 0}$ : difference between try-in paste and baseline, $r \mathrm{E}_{\mathrm{T2-T1}}$ : difference between cement before light-curing and try-in paste, and $\mathrm{rE}_{\mathrm{T}-\mathrm{T}}$ : difference between cement $24 \mathrm{~h}$ after light-curing and try-in paste.

Table 2. CIEDE2000 ( $\left.\mathrm{rE}_{00}\right)$ color measurement observed in each experimental set (mean \pm STD).

\begin{tabular}{|c|c|c|c|c|}
\hline \multirow{2}{*}{ Groups } & \multirow{2}{*}{ Thickness } & \multicolumn{3}{|c|}{ Time-points } \\
\hline & & $r E_{T 1-T 0}$ & $r E_{T 2-T 1}$ & $r E_{\text {T3-T1 }}$ \\
\hline \multirow{2}{*}{ AllCem veneer } & $0.5 \mathrm{~mm}$ & $2.86 \pm 0.42(\mathrm{~A}, \mathrm{a})$ & $9.64 \pm 1.40(\mathrm{~A}, \mathrm{~b})$ & $8.21 \pm 2.26(\mathrm{~A}, \mathrm{~b})$ \\
\hline & $1.0 \mathrm{~mm}$ & $1.76 \pm 1.01(\mathrm{~B}, \mathrm{a})$ & $2.09 \pm 0.92(\mathrm{~B}, \mathrm{a})$ & $2.27 \pm 1.07(\mathrm{~B}, \mathrm{a})$ \\
\hline \multirow{2}{*}{ Variolink veneer } & $0.5 \mathrm{~mm}$ & $0.73 \pm 0.46(A, a)$ & $1.63 \pm 0.75(A, b)$ & $1.06 \pm 0.75(\mathrm{~A}, \mathrm{a})$ \\
\hline & $1.0 \mathrm{~mm}$ & $1.22 \pm 0.70(\mathrm{~A}, \mathrm{ab})$ & $1.91 \pm 0.99(\mathrm{~A}, \mathrm{~b})$ & $0.74 \pm 0.28(\mathrm{~A}, \mathrm{a})$ \\
\hline
\end{tabular}

Different uppercase letters indicate statistically significant differences regarding $\Delta \mathrm{E}_{00}$ values in terms of thickness $(0.5 \mathrm{and} 1.0 \mathrm{~mm}$ thick) within a given commercial brand (Student T-test, $\mathrm{p}<0.05$ ). Different lowercase letters indicate statistically significant differences regarding $\Delta \mathrm{E}_{00}$ value in terms of time-points (one-way ANOVA for repeated measurements, $\mathrm{p}<0.05$ ). $\mathrm{rE}_{\mathrm{T} 1-\mathrm{TO}}$ : difference between try-in paste and baseline, $\mathrm{rE}_{\mathrm{T} 2-\mathrm{T}}$ : difference between cement before light-curing and try-in paste, and $\mathrm{rE}_{\mathrm{T3-T1}}$ : difference between cement $24 \mathrm{~h}$ after light-curing and try-in paste. 


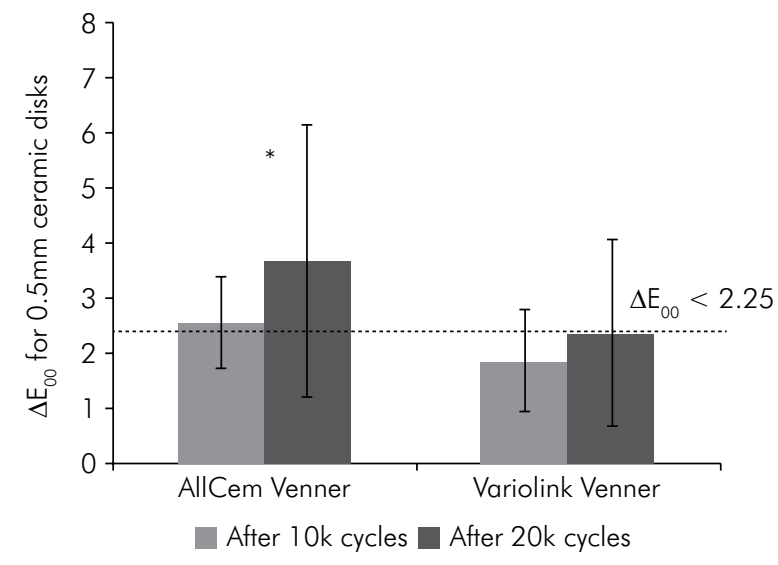

Figure 1. $r E_{00}$ values for analysis of color stability of $0.5 \mathrm{~mm}$ thick bonded ceramic disks after 10,000 and 20,000 thermal cycles. $\mathrm{rE}_{00}$ values lower than 2.25 were considered clinically imperceptible. ${ }^{*}$ indicates significant differences after 10,000 and 20,000 thermal cycles in the same brand.

visual ability of the evaluator, the viewing angle of the object, the color of the surroundings and the amount and type of light present, among other factors. ${ }^{14}$ Greater precision is possible when using spectrophotometric techniques compared to human visual recording in shade selection. ${ }^{33}$ Thus, the color measurements in this study were performed using a intraoral measurement device. The equipment used in this research features a daylight illuminator (D65), measuring the amount of light reflected by a colored sample. The CIE L*a*b* system and CIEDE2000, recommended by the American Dental Association (ADA) was used. ${ }^{28}$ According to this system, all colors were obtained from the mixture of the three basic colors (i.e. red, green and blue) in certain proportions, determined by coordinates that are organized in a three-dimensional form. ${ }^{11}$

It has been previously determined that color differences $\Delta \mathrm{E}=1$ for non-translucent materials can be detected in a controlled research setting at a rate of $50 \%$ of the observers under laboratory conditions. The perceptibility and acceptability values considered in this study were 1.74 and 3.46 units for $\mathrm{rE}_{\mathrm{ab}}$, and 1.25 and 2.25 units for $\mathrm{rE}_{00}$, respectively. ${ }^{28}$ Considering these parameters, for the group cemented with Variolink Veneer, both the $0.5 \mathrm{~mm}$ and $1.0 \mathrm{~mm}$ ceramics showed color correspondence between the try-in paste and the resin cement, obeying the referred threshold

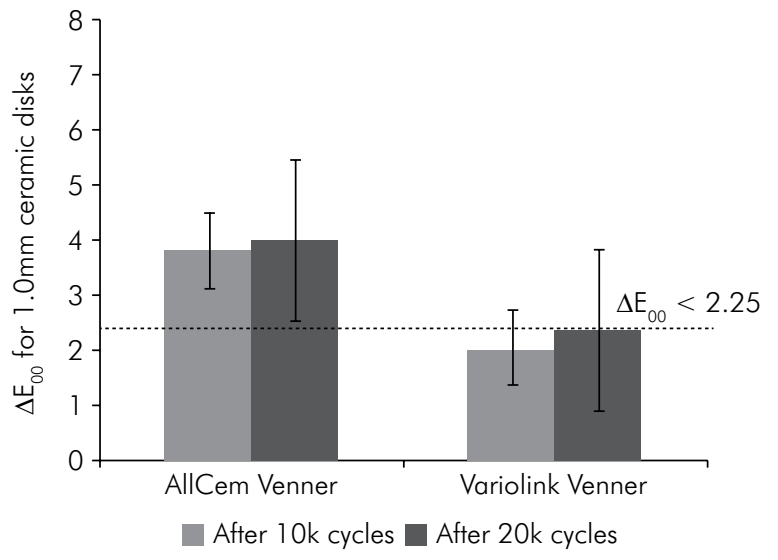

Figure 2. $\mathrm{rE}_{00}$ values for analysis of color stability of $1.0 \mathrm{~mm}$ thick bonded ceramic disks after 10,000 and 20,000 thermal cycles. $\mathrm{rE}_{00}$ values lower than 2.25 were considered clinically imperceptible ${ }^{*}$ indicates significant differences after 10,000 and 20,000 thermal cycles in the same brand.

of perceptibility and acceptability. These findings corroborate with the results reported earlier, ${ }^{19}$ since in general, no difference was observed between the color of the try-in pastes and their respective cements in different thicknesses of ceramics, although these previous studies used indirect resin composites rather than ceramic ceramics. For the AllCem Veneer system, the thickness of the ceramic significantly influenced the color measurement process. For this group, $\Delta \mathrm{E}$ values were considered acceptable only for $1.0 \mathrm{~mm}$ thickness, despite being clinically perceptible considering the threshold of 1.25 for $\mathrm{rE}_{00}{ }^{28}$

Although a previous study has observed correspondence between try-in pastes and cements after investigating several brands, ${ }_{1}^{16}$ it is worth noting that this study did not used protocols of surface treatment of the composite resin (phosphoric acid and adhesive) and of the ceramic ceramic (hydrofluoric acid and silane). In this study, all surface treatment protocols were applied according to manufacturers' instructions, which may explain the difference in results compared to previous studies. These results may suggest that surface treatment of the substrate and ceramics are also important factors in the final color reproduction.

Intrinsic or extrinsic factors may also explain the observed color performance. The intrinsic factors are related to variance in composition and physical- 
chemical reactions between try-in and resin cements, or to the oxidation of residual monomers in the resin cements. ${ }^{33,34,35}$ Thus, the initiator, the amount and type of monomer and the efficiency of the light-curing can affect the color correspondence. Light-curing may also have a significant influence on color changes since a higher degree of conversion leads to a lower amount of residual monomer available for the formation of colored degradation products. ${ }^{36,37}$

Therefore, try-in pastes should ideally be manufactured with the same or similar synthesis as the resin cement except for the absence of a polymerization system. However, try-in products are provided as water-soluble pastes for easier clinical application. Since the resin cements are essentially water-resistant methacrylate monomers, the organic part in the try-in pastes has been substituted by watersoluble glycerine. ${ }^{16}$ Thus, try-in pastes are a mixture of glycerine with all or several filler types utilized to formulate the corresponding resin cement and with suitable color pigments, as observed in Table 3 . The particular components, fillers and pigments aimed to provide try-in pastes with optical properties similar to the corresponding light-cured resin cements.

Table 3. Materials used and compositions.

\begin{tabular}{|c|c|c|c|c|}
\hline Product & Material & Manufacturer & Shade & Composition \\
\hline Llis & Resin composite & FGM, Joinville, SC, Brazil & $\mathrm{A} 2$ & $\begin{array}{l}\text { Bis-GMA, Bis-EMA, TEGDMA, } \\
\text { camphorquinone, co-initiators and silane }\end{array}$ \\
\hline IPS E.Max Press & $\begin{array}{l}\text { Disilicate } \\
\text { ceramic }\end{array}$ & Ivoclar Vivadent, Schaan, Liechtenstein & A2 & $\begin{array}{l}\text { Lithium disilicate reinforced pressable glass } \\
\text { ceramic }\end{array}$ \\
\hline Variolink Veneer & $\begin{array}{l}\text { Light-cured resin } \\
\text { cement }\end{array}$ & Ivoclar Vivadent, Schaan, Liechtenstein & 1 & $\begin{array}{c}\text { Dimethacrylates, inorganic fillers (silica, barium } \\
\text { glass, ytterbium trifluoride, catalysts and } \\
\text { stabilizers, pigments }\end{array}$ \\
\hline Variolink Veneer & Try-in paste & Ivoclar Vivadent, Schaan, Liechtenstein & 1 & Glycerin, mineral fillers and dyes \\
\hline AllCem Veneer & $\begin{array}{l}\text { Light-cured resin } \\
\text { cement }\end{array}$ & FGM, Joinville, SC, Brazil & A2 & $\begin{array}{c}\text { Methacrylic monomers, Barium-Alumino- } \\
\text { Silicate silanized glass particles, silicon dioxide, } \\
\text { camphorquinone, co-initiators, stabilizers, } \\
\text { pigments }\end{array}$ \\
\hline AllCem Veneer & Try-in paste & FGM, Joinville, SC, Brazil & A2 & $\begin{array}{c}\text { Polyethylene glycol (PEG), water, glycerin, } \\
\text { pigments and silica }\end{array}$ \\
\hline Condac 37 & Phosphoric acid & FGM, Joinville, SC, Brazil & Blue gel & 37\% Orthophosphoric acid \\
\hline Excite & $\begin{array}{l}\text { Two-step light } \\
\text { cure adhesive }\end{array}$ & Ivoclar Vivadent, Schaan, Liechtenstein & $\begin{array}{l}\text { Ambar } \\
\text { liquid }\end{array}$ & $\begin{array}{c}\text { HEMA, phosphoric acid acrylate, Bis-GMA, } \\
\text { dimethacrylate, highly dispersed silica, catalysts, } \\
\text { stabilizers and ethanol }\end{array}$ \\
\hline Ambar & $\begin{array}{l}\text { Two-step light } \\
\text { cure adhesive }\end{array}$ & FGM, Joinville, SC, Brazil & $\begin{array}{l}\text { Ambar } \\
\text { liquid }\end{array}$ & $\begin{array}{l}\text { Diurethane dimethacrylate, silane treated } \\
\text { silicondioxide, camphorquinone, ethyl } \\
\text { 4-dimethylaminobenzoate and ethanol }\end{array}$ \\
\hline Condac 10 & $\begin{array}{l}10 \% \text { Hydrofluoric } \\
\text { acid }\end{array}$ & FGM, Joinville, SC, Brazil & Red gel & $\begin{array}{c}\text { Hydrofluoric acid } 10 \% \text {, thickening agent, red } \\
\text { dye and purified water }\end{array}$ \\
\hline Monobond & Silane & Ivoclar Vivadent, Schaan, Liechtenstein & $\begin{array}{l}\text { Colorless } \\
\text { liquid }\end{array}$ & $\begin{array}{c}\text { One-bottle 3-methacryloyxypropyltrimethoxy } \\
\text { silane and water }\end{array}$ \\
\hline Prosil & Silane & FGM, Joinville, SC, Brazil & $\begin{array}{l}\text { Colorless } \\
\text { liquid }\end{array}$ & $\begin{array}{l}\text { One-bottle 3-methacryloyxypropyltrimethoxy } \\
\text { silane, ethanol and water }\end{array}$ \\
\hline
\end{tabular}


Regarding the thickness, there were no perceptible color changes for both resin cements in $1.0 \mathrm{~mm}$ ceramic disks, but values higher than 3.46 or 2.25 were observed for AllCem Veneer when the thickness decreased to $0.5 \mathrm{~mm}$. This indicates that the resin cement could slightly affect the resultant color of the ceramic disk when the thickness decreased. A similar conclusion is that the color correspondence is not always achieved in situations where the ceramic disk is thinner. ${ }^{6,10}$ One possible explanation for this observation is the presence of large amounts of initiator such as aromatic ketone (camphorquinone), which causes yellowish cement effects. A thinner material allows a greater amount of light to pass through. Thus, the color changes after light-curing were more evident in the presence of camphorquinone. ${ }^{38}$ Even for the $1.0 \mathrm{~mm}$-thick ceramics within the acceptable parameters, their values were higher than those observed for the Variolink veneer, further supporting our hypothesis regarding to the camphorquinone yellowing effect.

The composition of the Variolink system presents a smaller amount of initiating agents and a greater degree of monomer conversion, which is denoted by the greater stability of the cement..$^{12}$ In addition, the color in this system is checked by setting the values (-1, 0 and +1), while the AllCem veneer is observed based on hue differences (A1, A2, A3 etc.). Such differences suggest that, in a clinical situation, the use of try-in pastes that use the value scale may ensure greater predictability in color matching than systems using hue scales.

Resin-based cement agents may provide undesirable results over time, such as colorimetric modification. ${ }^{27}$ As the color of these materials changes over time, in vitro aging methods are correlated with the simulation of long clinical periods. ${ }^{30}$ Although several experimental protocols are known for investigating this behavior, thermal cycling is a more simple artificial aging method for study. ${ }^{30}$ This technique consists of immersions sequenced in cold $\left(5^{\circ} \mathrm{C}\right)$ and hot $\left(55^{\circ} \mathrm{C}\right)$ aqueous solutions capable of reproducing clinical situations, such as the ingestion of food and beverages of different temperatures. ${ }^{31}$ Since thermal cycling with 10,000 cycles was previously suggested to represent approximately a 1-year period under physiological conditions, the aging protocol essentially simulated 2 years of clinical use. ${ }^{36}$

With regards to the color stability, in both the 0.5 $\mathrm{mm}$ and $1.0 \mathrm{~mm}$ thick ceramics, no noticeable color changes were observed for the Variolink Veneer system. For the AllCem Veneer system however, values above 3.46 and 2.25 were observed at all values of $\mathrm{rE}$, regardless of the ceramic thickness. It is likely that the results obtained for the AllCem system are related to the individual composition, particularly the camphorquinone. ${ }^{32}$ Possible oxidation of this initiator may be responsible for dimming over time. ${ }^{38}$

The use of resin composite disks instead of dental substrate (i.e. enamel) on the set substrate/cement/ ceramic to verify color changes could be considered as a limitation of the study. Also, studies considering other brands and a greater variability of try-in and resin cements colors should be considered.

\section{Conclusion}

Within the limitations inherent to the present study, it is possible to conclude that the color correspondence between a try-in paste and its respective cement may vary according to resin cement composition. The Variolink Veneer system showed the lowest resin cement color difference relative to its corresponding try-in paste, and also presented color stability over time. Therefore, understanding how the color correspondence can vary between a try-in paste and its corresponding resin cement is worth examining for future clinical use.

\section{Acknowledgements}

The authors would like to thank the Fundação de Amparo à Pesquisa e Desenvolvimento Científico do Maranhão, FAPEMA (Portuguese acronym for the Maranhão State Research Foundation) for supporting the publication of this article. 


\section{References}

1. Jordan A. Clinical aspects of porcelain laminate veneers: considerations in treatment planning and preparation design. J Calif Dent Assoc. 2015 Apr;43(4):199-202.

2. Almeida JR, Schmitt GU, Kaizer MR, Boscato N, Moraes RR. Resin-based luting agents and color stability of bonded ceramic veneers. J Prosthet Dent. 2015 Aug;114(2):272-7. https://doi.org/10.1016/i.prosdent.2015.01.008

3. Peumans M, Van Meerbeek B, Lambrechts P, Vuylsteke-Wauters M, Vanherle G. Five-year clinical performance of porcelain veneers. Quintessence Int. 1998 Apr;29(4):211-21.

4. Pippin DJ, Mixson JM, Soldan-Els AP. Clinical evaluation of restored maxillary incisors: veneers vs. PFM crowns. J Am Dent Assoc. 1995 Nov;126(11):1523-9. https://doi.org/10.14219/jada.archive.1995.0081

5. Siögren G, Lantto R, Granberg A, Sundström BO, Tillberg A. Clinical examination of leucite-reinforced glass-ceramic crowns (Empress) in general practice: a retrospective study. Int J Prosthodont. 1999 Mar-Apr;12(2):122-8.

6. Xu B, Chen X, Li R, Wang Y, Li Q. Agreement of try-in pastes and the corresponding luting composites on the final color of ceramic veneers. J Prosthodont. 2014 Jun;23(4):308-12. https://doi.org/10.1111/jopr.12109

7. Horn HR. Porcelain laminate veneers bonded to etched enamel. Dent Clin North Am. 1983 Oct;27(4):671-84.

8. Turgut S, Bagis B. Effect of resin cement and ceramic thickness on final color of laminate veneers: an in vitro study. J Prosthet Dent. 2013 Mar;109(3):179-86. https://doi.org/10.1016/S0022-3913(13)60039-6

9. Begum Z, Chheda P, Shruthi CS, Sonika R. Effect of ceramic thickness and luting agent shade on the color masking ability of ceramic veneers. J Indian Prosthodont Soc. 2014 Dec;14(S1 Suppl 1):46-50. https://doi.org/10.1007/s13191-014-0362-2

10. Davis BK, Aquilino SA, Lund PS, Diaz-Arnold AM, Denehy GE. Colorimetric evaluation of the effect of porcelain opacity on the resultant color of porcelain veneers. Int J Prosthodont. 1992 Mar-Apr;5(2):130-6.

11. Rigoni P, Amaral FL, França FM, Basting RT. Color agreement between nanofluorapatite ceramic discs associated with try-in pastes and with resin cements. Braz Oral Res. 2012 Nov-Dec;26(6):516-22. https://doi.org/10.1590/S1806-83242012000600006

12. Chu FC, Chow TW, Chai J. Contrast ratios and masking ability of three types of ceramic veneers. J Prosthet Dent. 2007 Nov; $98(5): 359-64$. https://doi.org/10.1016/S0022-3913(07)60120-6

13. Yaman P, Qazi SR, Dennison JB, Razzoog ME. Effect of adding opaque porcelain on the final color of porcelain laminates. J Prosthet Dent. 1997 Feb;77(2):136-40. https://doi.org/10.1016/S0022-3913(97)70226-9

14. Joiner A. Tooth colour: a review of the literature. J Dent. 2004;32 Suppl 1:3-12. https://doi.org/10.1016/i.jdent.2003.10.013

15. Cubas GBA, Camacho GB, Demarco FF, Pereira-Cenci T. The effect of luting agents and ceramic thickness on the color variation of different ceramics against a chromatic background. Eur J Dent. 2011 Jul;5(3):245-52.

16. Kampouropoulos D, Gaintantzopoulou M, Papazoglou E, Kakaboura A. Colour matching of composite resin cements with their corresponding try-in pastes. Eur J Prosthodont Restor Dent. 2014 Jun;22(2):84-8. https://doi.org/10.1922/EJPRD_1340Papazoglou05

17. Taschner M, Frankenberger R, García-Godoy F, Rosenbusch S, Petschelt A, Krämer N. IPS Empress inlays luted with a self-adhesive resin cement after 1 year. Am J Dent. 2009 Feb;22(1):55-9.

18. ALGhazali N, Laukner J, Burnside G, Jarad FD, Smith PW, Preston AJ. An investigation into the effect of try-in pastes, uncured and cured resin cements on the overall color of ceramic veneer restorations: an in vitro study. J Dent. 2010;38 Suppl 2:e78-86. https://doi.org/10.1016/i. jdent.2010.08.013

19. Xing W, Jiang T, Ma X, Liang S, Wang Z, Sa Y, et al. Evaluation of the esthetic effect of resin cements and try-in pastes on ceromer veneers. J Dent. 2010;38 Suppl 2:e87-94. https://doi.org/10.1016/i.jdent.2010.05.007

20. Della Bona A, Northeast SE. Shear bond strength of resin bonded ceramic after different try-in procedures. J Dent. 1994 Apr;22(2):103-7. https://doi.org/10.1016/0300-5712(94)90012-4

21. Balderamos LP, O'Keefe KL, Powers JM. Color accuracy of resin cements and try-in pastes. Int J Prosthodont. 1997 Mar-Apr;10(2):111-5. PMID:9206449

22. Vaz EC, Vaz MM, de Torres EM, de Souza JB, Barata TJ, Lopes LG. Resin cement: correspondence with try-in paste and influence on the immediate final color of veneers. J Prosthodont. 2018 Jan 3. https://doi.org/10.1111/jopr.12728

23. Karaagaclioglu L, Yilmaz B. Influence of cement shade and water storage on the final color of leucite-reinforced ceramics. Oper Dent. 2008 Jul-Aug;33(4):386-91. https://doi.org/10.2341/07-61

24. Terzioğlu H, Yilmaz B, Yurdukoru B. The effect of different shades of specific luting agents and IPS empress ceramic thickness on overall color. Int J Periodontics Restorative Dent. 2009 Oct;29(5):499-505.

25. Jorgenson MW, Goodkind RJ. Spectrophotometric study of five porcelain shades relative to the dimensions of color, porcelain thickness, and repeated firings. J Prosthet Dent. 1979 Jul;42(1):96-105. https://doi.org/10.1016/0022-3913(79)90335-4

26. Nimeroff I. Colorimetry: National Bureau of Standards. Washington, DC: Editora; 1968. 
- Correspondence between try-in pastes and resin cements, and color stability of bonded lithium disilicate disks

27. Sharma G, Wu W, Dalal EN. The CIEDE2000 color-difference formula: implementation notes, supplementary test data, and mathematical observations. Color Res Appl. 2005;30(1):21-30. https://doi.org/10.1002/col.20070

28. Ghinea R, Pérez MM, Herrera LJ, Rivas MJ, Yebra A, Paravina RD. Color difference thresholds in dental ceramics. J Dent. 2010;38 Suppl 2:e57-64. https://doi.org/10.1016/i.jdent.2010.07.008

29. Paul S, Peter A, Pietrobon N, Hämmerle CH. Visual and spectrophotometric shade analysis of human teeth. J Dent Res. 2002 Aug;81(8):57882. https://doi.org/10.1177/154405910208100815

30. Samra AP, Pereira SK, Delgado LC, Borges CP. Color stability evaluation of aesthetic restorative materials. Braz Oral Res. 2008 JulSep;22(3):205-10. https://doi.org/10.1590/S1806-83242008000300003

31. Paravina RD, Ontiveros JC, Powers JM. Accelerated aging effects on color and translucency of bleaching-shade composites. J Esthet Restor Dent. 2004;16(2):117-26. https://doi.org/10.1111/j.1708-8240.2004.tb00018.x

32. Hekimoğlu C, Anil N, Etikan I. Effect of accelerated aging on the color stability of cemented laminate veneers. Int J Prosthodont. 2000 Jan-Feb;13(1):29-33.

33. Kucukesmen HC, Usumez A, Ozturk N, Eroglu E. Change of shade by light polymerization in a resin cement polymerized beneath a ceramic restoration. J Dent. 2008 Mar;36(3):219-23. https://doi.org/10.1016/i.jdent.2007.12.005

34. Janda R, Roulet JF, Latta M, Kaminsky M, Rüttermann S. Effect of exponential polymerization on color stability of resin-based filling materials. Dent Mater. 2007 Jun;23(6):696-704. https://doi.org/10.1016/i.dental.2006.06.009

35. Morley F, Stockwell PB. A simple thermal cycling device for testing dental materials. J Dent. 1977 Mar;5(1):39-41. https://doi.org/10.1016/ S0300-5712(77)80022-5

36. Gale MS, Darvell BW. Thermal cycling procedures for laboratory testing of dental restorations. J Dent. 1999 Feb;27(2):89-99. https://doi. org/10.1016/S0300-5712(98)00037-2

37. Shintani H, Inove T, Yamaki M. Analysis of camphorquinone in visible light-cured composite resins. Dent Mater. 1985 Aug;1(4):124-6. https://doi.org/10.1016/S0109-5641(85)80002-6

38. Alvim HH, Alécio AC, Vasconcellos WA, Furlan M, Oliveira JE, Saad JR. Analysis of camphorquinone in composite resins as a function of shade. Dent Mater. 2007 Oct;23(10):1245-9. https://doi.org/10.1016/i.dental.2006.11.002 